\title{
A bi-objective weighted model for improving the discrimination power in MCDEA
}

\author{
Ghasemi, M.R. a, Joshua Ignatius ${ }^{\text {a1 }}$, Ali Emrouznejad \\ ${ }^{a}$ School of Mathematical Sciences, Universiti Sains Malaysia, Penang, Malaysia \\ ${ }^{\mathrm{b}}$ Aston Business School, Aston University, Birmingham B4 7ET, UK
}

\begin{abstract}
Lack of discrimination power and poor weight dispersion remain major contention issues in Data Envelopment Analysis (DEA) models, which have also hampered the developments in the multiobjective DEA domain. Since the initial multi- criteria DEA (MCDEA) model of Li and Reeves ( 1999), only one other research by Bal, Örkcü and Çelebioğlu ( 2010) attempted to solve the MCDEA framework through two goal programming approaches, i.e. GPDEA-CCR and GPDEA-BCC. It was claimed that both models improved upon the discrimination power of DEA by balancing the distribution of input-output weights. It was also claimed that both GPDEA models are major improvements to the original MCDEA of Li and Reeves (1999). In this research we first checked the validity of GPDEA models and found that they do not improve the discrimination power as it has been claimed, we further propose an alternative solution to the formulation using bi-objective linear programming. It is shown that the proposed bi-objective multiple criteria DEA(BiO-MCDEA) performs better than the GPDEA models in the aspects of discrimination power and weight dispersion, as well as requiring less computational codes. An application of energy dependency among 26 European Union member countries is further used to describe the efficacy of our approach.
\end{abstract}

Key words: Data envelopment analysis, Multiple criteria data envelopment analysis, Goal programming, Discrimination power.

\section{Introduction}

Data envelopment analysis (DEA) was first proposed by Charnes et al. (Charnes, Cooper, \& Rhodes, 1978) and remained the leading technique for measuring the relative efficiency of decision-making units (DMUs) based on their respective multiple inputs and outputs. DEA has been the fastest growing discipline in the past three decades covering easily over a thousand papers in the Operations Research and Management Science discipline (see (Emrouznejad, Parker, \& Tavares, 2008)). The efficiency of a

\footnotetext{
${ }^{1}$ Corresponding author: Joshua Ignatius, School of Mathematical Sciences, Universiti Sains Malaysia, Penang, Malaysia
} 
DMU is defined as a weighted sum of its outputs divided by the weighted sum of its inputs on a bounded ratio scale.

One of the drawbacks of the DEA is the problem of lack of discrimination among efficient decision making units (DMUs) and hence yielding many DMUs as efficient. The problem is noted when the number of DMUs evaluated is significantly lesser than the number of inputs and outputs used in the evaluation. The weights derived post-hoc from the evaluation exercise may reveal that some inputs or outputs have zero values. This is counter-intuitive especially in a decision making exercise, where one expects to use all the inputs and output values that are rated for the DMUs. Hence, it further implies that some of the variables were not used in the evaluation exercise in achieving the final ranking. On the contrary, unrealistic weight distribution for DEA also occurs when some DMUs are rated as efficient because of extreme large weights in a single output and/or extreme small weights in a single input.

Thompson et al. ( 1986) are among the first authors to propose the use of weight restriction to increase the discrimination power of DMUs. The issue was immediately picked up by many authors, including Dyson and Thanassoulis (Dyson \& Thanassoulis, 1988), Charnes et al. (Charnes, Cooper, Huang, \& Sun, 1990a), Thanassoulis et al. (Thanassoulis \& Allen, 1998). Hence, several methods such as assurance region (AR) procedure (R. G. Thompson, Langemeier, Lee, \& Thrall, 1990), cone ratio envelopment (Charnes, Cooper, Huang, \& Sun, 1990b) area adressed in the literature as strategies to solve problems arising from unrealistic weight distribution. Subsequently, other DEA models were introduced in the literature to overcome the discriminant power problems, such as the cross-efficiency evaluation technique (Anderson, Hollingsworth, \& Inman, 2002; Doyle \& Green, 1994, 1995; Green, Doyle, \& Cook, 1996; Sexton, Silkman, \& Hogan, 1986), super-efficiency model (Andersen \& Petersen, 1993; Y. Chen, 2005), and multiple criteria (or multi-objective) DEA (Y.-W. Chen, Larbani, \& Chang, 2009; Li \& Reeves, 1999).

The focus in this paper is on the most recent development in the area; that is, to introduce a weighted model for improving the discrimination power and weight dispersion, which focuses on multiple criteria Data Envelopment Analysis (MCDEA). The rest of the paper is organized as follows. Section 2 gives a brief description of the multiple criteria data envelopment analysis (MCDEA) and the more recent goal programming data envelopment analysis (GPDEA) as a procedure for MCDEA. Section 3 highlights some drawbacks on using GPDEA to represent MCDEA analysis. We therefore introduce an alternative bi-objective multiple criteria model (BiO-MCDEA) to improve the discrimination power of MCDEA in Section 4. An application of energy dependency among 26 EU member countries demonstrates the efficacy of the model in Section 5. Concluding remarks are given in Section 6.

\section{Improving discrimination power in DEA: Recent developments}




\section{Multiple criteria data envelopment analvsis (MCDEA)}

The MCDEA model; consisting of three objectives, was proposed by Li and Reeves (Li\&Reeves, 1999) to improve the discriminating power of classical DEA model. Classical definition of relative efficiency is considered one of the criteria in this model, hence the classical DEA solution is said to be contained in the set of MCDEA solutions. In other words, a wider solution is possible with MCDEA, so as to gain more reasonable input and output weights. Another 2 objectives are the Minimax and Minsum criteria.

In MCDEA, the three objectives are analyzed separately; one at a time, and no preference order was set for those objectives. The solutions derived from each run are considered non-dominated in the multi objective linear programming (MOLP) sense. Li and Reeves (Li \& Reeves, 1999) note that generally the Minimax criterion is more restrictive than the Minsum criterion, while the first criterion is the least restrictive of all. Since the Minimax and Minsum criteria tend to provide less number of efficient DMUs as compared to the first criteria, it is said to provide better discriminating power than a classical DEA model. As such, the Minimax and Minsum criteria are helpful when the number of DMUs is significantly larger than the number of inputs and outputs used for evaluation.

Consider in evaluating the relative efficiency of $n$ DMUs which use $m$ inputs $\left(x_{i}, i=1, \ldots, m\right)$ to produce $s$ outputs $\left(y_{j}, j=1, \ldots, s\right)$. The MCDEA model proposed by Li and Reeves (Li\&Reeves, 1999) which considers three objective functions: i) minimizing $d_{o}$ (or maximizing $\theta_{o}$ ), ii) minimizing the maximum deviation, and iii) minimizing the sum of deviation, is defined as follows in Model 1:

Model 1: Multi criteria data envelopment analysis

$$
\begin{aligned}
& \min d_{o}\left(\text { or } \max \theta_{o}=\sum_{r=1}^{s} u_{r} y_{r o}\right) \\
& \min M \\
& \min \sum_{j=1}^{n} d_{j} \\
& \quad \sum_{i=1}^{m} v_{i} x_{i o}=1, \\
& \quad \sum_{r=1}^{s} u_{r} y_{r j}-\sum_{i=1}^{m} v_{i} x_{i j}+d_{j}=0, \quad j=1, \ldots, n, \\
& \quad M-d_{j} \geq 0, \quad j=1, \ldots, n,
\end{aligned}
$$




$$
\begin{aligned}
& u_{r} \geq 0, \quad r=1, \ldots, s, \\
& v_{i} \geq 0, \quad i=1, \ldots, m, \\
& d_{j} \geq 0, \quad j=1, \ldots, n,
\end{aligned}
$$

The quantity $d_{o}$ in the first objective function is bounded on an interval $[0,1)$ and is regarded as a measure of inefficiency. Thus, DMU $o$ is efficient at $h_{o}=1-d_{o}$ where $h_{o}$ is the efficiency measure in a classical DEA. In short, the first objective function (i.e. $\min d_{o}\left(\right.$ or $\left.\left.\max \theta_{o}=\sum_{r=1}^{s} u_{r} y_{r o}\right)\right)$ is equivalent to the objective function of a classical DEA. The $M$ in the second objective function (minmax criterion) represents the maximum quantity of all deviation variables $d_{j}(j=1, \ldots, n)$. The third objective function is a Minsum of all deviation variables. Another noteworthy point is the introduction of the $M-d_{j} \geq 0,(j=1, \ldots, n)$ constraint in MCDEA, which does not alter the feasible region of the solution but merely to ensure that $\max d_{j} \geq 0$.

\section{Goal programming DEA models (GPDEA)}

Li and Reeves (Li\&Reeves, 1999) did not suggest a solution for their proposed MCDEA model that optimizes all objectives simultaneously. The aim of their proposed MCDEA model solution process is not to extract an optimal solution; but instead, to find a series of non-dominated solutions that is left to the analyst in selecting the most preferred one, if need be. Therefore, goal programming as a solution for the MCDEA model can be seen as a natural progression in converting the multiple objective programming in the MCDEA model into a single objective problem.

Goal programming is a type of multi-objective optimization, also known as multiple-criteria decision making which can provide a way of striving toward several such objectives simultaneously. The basic approach of goal programming is to establish a specific numeric goal for each of the objectives, formulate an objective function for each objective, and then seek a solution that minimizes the (weighted) sum of unwanted deviations of these objective functions from their respective goals.

Bal et al. (Bal, et al., 2010) recently proposed the following goal programming to solve the formulation proposed by Li and Reeves (Li \& Reeves, 1999). The former adopted the non-weighted approach in their solution design and claimed to be an equivalent single objective form to the latter's three objectives. 
Model 2: Goal programming data envelopment analysis under CRS

$$
\begin{aligned}
& \min a=\left\{d_{1}^{-}+d_{1}^{+}+d_{2}^{+}+\sum_{j} d_{3 j}^{-}+\sum_{j} d_{j}\right\} \\
& \sum_{i=1}^{m} v_{i} x_{i o}+d_{1}^{-}-d_{1}^{+}=1, \\
& \sum_{r=1}^{s} u_{r} y_{r o}+d_{2}^{-}-d_{2}^{+}=1, \\
& \sum_{r=1}^{s} u_{r} y_{r j}-\sum_{i=1}^{m} v_{i} x_{i j}+d_{j}=0, \quad j=1, \ldots, n, \\
& M_{-} d_{j}+d_{3 j}^{-}-d_{3 j}^{+}=0, \quad j=1, \ldots, n, \\
& u_{r} \geq 0, \quad r=1, \ldots, s, \\
& v_{i} \geq 0, \quad i=1, \ldots, m, \\
& d_{j} \geq 0, \quad j=1, \ldots, n, \\
& d_{1}^{-}, d_{1}^{+}, d_{2}^{-}, d_{2}^{+} \geq 0, \\
& d_{3 j}^{-}, d_{3 j}^{+} \geq 0, \quad j=1, \ldots, n,
\end{aligned}
$$

The above model is with the assumption of constant returns to scale (CRS) (Bal, et al., 2010), where $d_{1}^{-}$ and $d_{1}^{+}$are the unwanted deviations for the goal which the weighted sum of inputs equal to unity, $d_{2}^{-}$and $d_{2}^{+}$are the wanted and unwanted deviation variables which make the weighted sum of outputs less than or equal to one, whereas $d_{3 j}^{-}$and $d_{3 j}^{+}(j=1, \ldots, n)$ are the unwanted and wanted deviation variables for the goal $M-d_{j} \geq 0(j=1, \ldots, n) . M$ remains as the maximum deviation $d_{j}$, for $\operatorname{DMU}_{j}(\mathrm{j}=1, \ldots, \mathrm{n})$, which is also an unwanted deviation. A similar model under the variable returns to scale (VRS) assumption is placed in Appendix 1.

The achievement objective function $\left\{d_{1}^{-}+d_{1}^{+}+d_{2}^{+}+\sum_{j} d_{3 j}^{-}+\sum_{j} d_{j}\right\}$ states that all deviations have been given equal weights. In the GPDEA's case, minimizing the unwanted deviations from the goal values are to be desired (Ignizio, 1976; lee, 1972). However, there are fundamental flaws associated with the GPDEA model, ranging from the interpretation of a goal programming method to the reported results. We highlight some of these issue separately in the next section. 


\section{Some drawbacks on both GPDEA models}

The purpose of this section is to highlight some drawbacks of the GPDEA models, which will help us to further develop the new bi-objective multiple criteria DEA (BiO-MCDEA) model in Section 4.

\section{The validity of GPDEA and the issue of zero weights for all variables in some DMUs}

We were initially intrigued by the use of goal programming as a means to achieve greater weight dispersion and discrimination power among criteria in DEA. When attempting to reproduce the analysis in Bal et al. (Bal, et al., 2010), we have noted some methodological and formulation problems. We found some of these problems to be consistent for all datasets in Bal et al (Bal, et al., 2010). However, for the purpose of illustrating the inappropriateness of the GPDEA models, we only explain the solutions of 'dataset 1' and 'university dataset' in Bal et al (Bal, et al., 2010).

Let us first start with the hypothetical dataset consisting of 10 DMUs with four inputs and four outputs (see Table 1- which is reproduced from Bal et al. (Bal, et al., 2010) for ease of reference).

Table 1

Example 1 dataset

\begin{tabular}{|c|c|c|c|c|c|c|c|c|}
\hline \multirow[t]{2}{*}{ DMU } & \multicolumn{4}{|c|}{ Outputs } & \multicolumn{4}{|c|}{ Inputs } \\
\hline & $\mathrm{y}_{1}$ & $\mathrm{y}_{2}$ & $\mathrm{y}_{3}$ & $\mathrm{y}_{4}$ & $\mathrm{x}_{1}$ & $\mathrm{x}_{2}$ & $\mathrm{x}_{3}$ & $\mathrm{x}_{4}$ \\
\hline 1 & 47 & 93 & 54 & 65 & 32 & 50 & 82 & 46 \\
\hline 2 & 88 & 56 & 92 & 80 & 61 & 56 & 68 & 37 \\
\hline 3 & 94 & 65 & 80 & 80 & 42 & 58 & 45 & 34 \\
\hline 4 & 50 & 53 & 93 & 97 & 73 & 39 & 88 & 81 \\
\hline 5 & 47 & 42 & 70 & 52 & 45 & 38 & 68 & 41 \\
\hline 6 & 86 & 45 & 100 & 47 & 86 & 62 & 44 & 32 \\
\hline 7 & 83 & 91 & 62 & 74 & 38 & 74 & 71 & 74 \\
\hline 8 & 79 & 60 & 72 & 98 & 61 & 54 & 70 & 62 \\
\hline 9 & 85 & 68 & 51 & 41 & 84 & 52 & 38 & 47 \\
\hline 10 & 78 & 95 & 70 & 92 & 87 & 47 & 31 & 52 \\
\hline
\end{tabular}

We used Model 1 formulation for both CRS and VRS assumptions to reproduce the results as depicted in Table 2 and Table 3. It is easy to observe that the true efficiency values differ significantly from the ones reported in Bal et al. (Bal, et al., 2010). More importantly, we examined the weights and noticed contrary to what had been claimed in Bal et al. (Bal, et al., 2010), the input-output weights and efficiency values for some DMUs could attain zero values for all variables. For example in this case, zero weights assigned to all variables for $\mathrm{DMU}_{1}$ (under CRS) and $\mathrm{DMU}_{5}$ (under CRS and VRS). This just disproves the "...improvement of the dispersion of input-output weights and the improvement of discrimination power..." as claimed in Bal et al. (Bal, et al., 2010). This is problematic when some of the efficiency 
values can be 1 at the same instance, thus confirming the inability for the input and output weights to translate into technical efficiency effectively (see appendix 2 for proof).

It is rather quite simple to reason where the problem lies. As one can easily observe in the next section, we impose some restrictions on the weights to avoid this issue. In an input-oriented model, it is necessary to set the constraint $\sum_{i=1}^{m} v_{i} x_{i o}=1$, and seek to achieve an output that is as high as possible. This is a fundamental aspect of scaling and benchmarking, where one has to fix either the sum of input or the sum of output to be 1, before proceeding to determine the other. In Bal et al.'s case (Bal, et al., 2010), they chose to set both $\sum_{i=1}^{m} v_{i} x_{i o}+d_{1}^{-}-d_{1}^{+}=1$ and $\sum_{r=1}^{s} u_{r} y_{r o}+d_{2}^{-}-d_{2}^{+}=1$. It stands to reason that proper scaling cannot be achieved in this manner as the model is neither input nor output oriented. Even if we eliminate $\sum_{r=1}^{s} u_{r} y_{r o}+d_{2}^{-}-d_{2}^{+}=1$, there is a possibility for $0 \leq \sum_{i=1}^{m} v_{i} x_{i o} \leq 1$ due to the minimization of $d_{1}^{-}-d_{1}^{+}$in the objective function.

\section{Table 2}

GPDEA-CCR results based on example 1 dataset

\begin{tabular}{|c|c|c|c|c|c|c|c|c|c|c|}
\hline \multirow[t]{2}{*}{$\overline{\mathrm{DMU}}$} & \multicolumn{4}{|c|}{ Output weights } & \multicolumn{4}{|c|}{ Input weights } & \multirow{2}{*}{$\begin{array}{l}\text { Efficiency } \\
\text { true values }\end{array}$} & \multirow{2}{*}{$\begin{array}{l}\text { Efficiency } \\
\text { Provided by Ba }\end{array}$} \\
\hline & $\mathrm{u}_{1}$ & $\mathrm{u}_{2}$ & $\mathrm{u}_{3}$ & $\mathrm{u}_{4}$ & $\mathrm{v}_{1}$ & $\mathrm{v}_{2}$ & $\mathrm{v}_{3}$ & $\mathrm{v}_{4}$ & & \\
\hline 1 & $\mathbf{0}$ & $\mathbf{0}$ & $\mathbf{0}$ & $\mathbf{0}$ & $\mathbf{0}$ & $\mathbf{0}$ & $\mathbf{0}$ & $\mathbf{0}$ & $\mathbf{0}$ & 0.968 \\
\hline 2 & 0.00317 & 0.00434 & 0.00464 & $\mathbf{0}$ & 0.00403 & 0.0135 & 0 & 0 & 0.948 & 0.951 \\
\hline 3 & 0.00333 & 0.00456 & 0.00488 & $\mathbf{0}$ & 0.00424 & 0.0142 & 0 & 0 & 1 & 1 \\
\hline 4 & 0 & 0.00488 & 0.00797 & $\mathbf{0}$ & 0.00336 & 0.0118 & 0.0006 & 0.003 & 1 & 1 \\
\hline 5 & $\mathbf{0}$ & $\mathbf{0}$ & $\mathbf{0}$ & $\mathbf{0}$ & $\mathbf{0}$ & $\mathbf{0}$ & $\mathbf{0}$ & $\mathbf{0}$ & $\mathbf{0}$ & 0.95 \\
\hline 6 & 0.00268 & 0.00367 & 0.00392 & $\mathbf{0}$ & 0.00341 & 0.0114 & 0 & 0 & 0.788 & 0.794 \\
\hline 7 & 0.0007 & 0.00371 & 0.00564 & $\mathbf{0}$ & 0.00245 & 0.0099 & 0 & 0.002 & 0.745 & 0.779 \\
\hline 8 & 0.00084 & 0.00446 & 0.00679 & $\mathbf{0}$ & 0.00295 & 0.0119 & 0 & 0.003 & 0.823 & 0.843 \\
\hline 9 & 0.00305 & 0.00417 & 0.00446 & $\mathbf{0}$ & 0.00388 & 0.013 & 0 & 0 & 0.771 & 0.767 \\
\hline 10 & 0.00322 & 0.00441 & 0.00471 & $\mathbf{0}$ & 0.00409 & 0.0137 & 0 & 0 & 1 & 1 \\
\hline
\end{tabular}


Table 3

GPDEA-BCC results based on example 1 dataset

\begin{tabular}{|c|c|c|c|c|c|c|c|c|c|c|}
\hline \multirow[t]{2}{*}{$\mathrm{DMU}$} & \multicolumn{4}{|c|}{ Output weights } & \multicolumn{4}{|c|}{ Input weights } & \multirow{2}{*}{$\begin{array}{l}\text { Efficiency } \\
\text { true values }\end{array}$} & \multirow{2}{*}{$\begin{array}{l}\text { Efficiency } \\
\text { Provided by Bal }\end{array}$} \\
\hline & $\mathrm{u}_{1}$ & $\mathrm{u}_{2}$ & $\mathrm{u}_{3}$ & $\mathrm{u}_{4}$ & $\mathrm{v}_{1}$ & $\mathrm{v}_{2}$ & $\mathrm{v}_{3}$ & $\mathrm{~V}_{4}$ & & \\
\hline 1 & 0.00762 & 0 & 0.00172 & 0 & 0.00155 & 0.019 & 0 & 0 & 0.765 & 0.971 \\
\hline 2 & 0.0034 & 0.00328 & 0.00307 & 0 & 0.00368 & 0.0138 & 0 & 0 & 0.945 & 0.951 \\
\hline 3 & 0.00355 & 0.00343 & 0.00321 & $\mathbf{0}$ & 0.00385 & 0.0145 & 0 & 0 & 1 & 1 \\
\hline 4 & 0 & 0.005 & 0.00821 & $\mathbf{0}$ & 0.00314 & 0.0119 & 0.0003 & 0.003 & 1 & 1 \\
\hline 5 & $\mathbf{0}$ & $\mathbf{0}$ & $\mathbf{0}$ & $\mathbf{0}$ & $\mathbf{0}$ & $\mathbf{0}$ & $\mathbf{0}$ & $\mathbf{0}$ & $\mathbf{0}$ & 0.961 \\
\hline 6 & 0.00289 & 0.00279 & 0.00261 & $\mathbf{0}$ & 0.00313 & 0.0118 & 0 & 0 & 0.788 & 0.965 \\
\hline 7 & 0.0052 & 0 & 0.00118 & $\mathbf{0}$ & 0.00106 & 0.013 & 0 & 0 & 0.718 & 0.798 \\
\hline 8 & 0.00349 & 0.00338 & 0.00316 & $\mathbf{0}$ & 0.00379 & 0.0142 & 0 & 0 & 0.89 & 1 \\
\hline 9 & 0.0033 & 0.00319 & 0.00298 & $\mathbf{0}$ & 0.00358 & 0.0135 & 0 & 0 & 0.824 & 0.909 \\
\hline 10 & 0.0035 & 0.00338 & 0.00316 & 0 & 0.00379 & 0.0143 & 0 & 0 & 1 & 1 \\
\hline
\end{tabular}

\section{The validity of GPDEA when compared with the results of MCDEA}

To explore the results of MCDEA models we further compared the results of GPDEA with MCDEA. We discovered that the GPDEA models do not conduct nor achieve the same purposes as the MCDEA model. MCDEA model uses non-dominated solutions and each objective is handled one at a time; hence unlike the GPDEA models, MCDEA does not attempt to get a global optimal value but more towards generating a series of non-dominated solutions interactively. In other words, MCDEA can be used to achieve either a stricter or more lenient solution set, depending on whether more or less number of efficient DMUs are sought by the analyst in the decision making process.

We recomputed the results of the MCDEA model of Li and Reeves using the Minsum objective function of $\sum_{j} d_{j}$ and reproduce them in Table 4 (CRS) and Table 5 (VRS). If one would compare the efficiency values of Table 4 and Table 5 with the GPDEA models of Table 2 and Table 3, the observation would yield similar efficiency values. Again, the comparison has to be made on the corrected values denoted as 'true values' in Table 2 and Table 3 and not the 'values reported in Bal et al. (2010)'. In summary, we found that the GPDEA models' achievement objective function $\left\{d_{1}^{-}+d_{1}^{+}+d_{2}^{+}+\sum_{j} d_{3 j}^{-}+\sum_{j} d_{j}\right\}$ cannot handle all three criteria of the MCDEA model. 
Table 4

\begin{tabular}{|c|c|c|c|c|c|c|c|c|c|}
\hline \multirow[t]{2}{*}{$\mathrm{DMU}$} & \multicolumn{4}{|c|}{ Output weights } & \multicolumn{4}{|c|}{ Input weights } & \multirow[t]{2}{*}{ Efficiency } \\
\hline & $\mathrm{u}_{1}$ & $\mathrm{u}_{2}$ & $\mathrm{u}_{3}$ & $\mathrm{u}_{4}$ & $\mathrm{v}_{1}$ & $\mathrm{v}_{2}$ & $\mathrm{v}_{3}$ & $\mathrm{v}_{4}$ & \\
\hline 1 & 0.00102 & 0.00543 & 0.00827 & $\mathbf{0}$ & 0.00359 & 0.01453 & 0 & 0.0034 & 1 \\
\hline 2 & 0.00317 & 0.00434 & 0.00464 & $\mathbf{0}$ & 0.00403 & 0.01347 & 0 & 0 & 0.948 \\
\hline 3 & 0.00333 & 0.00456 & 0.00488 & $\mathbf{0}$ & 0.00424 & 0.01417 & 0 & 0 & 1 \\
\hline 4 & 0 & 0.00488 & 0.00797 & $\mathbf{0}$ & 0.00336 & 0.01182 & 0.0006 & 0.003 & 1 \\
\hline 5 & 0.00119 & 0.00636 & 0.00967 & $\mathbf{0}$ & 0.0042 & 0.01699 & 0 & 0.004 & 1 \\
\hline 6 & 0.00268 & 0.00367 & 0.00392 & $\mathbf{0}$ & 0.00341 & 0.0114 & 0 & 0 & 0.788 \\
\hline 7 & 0.0007 & 0.00371 & 0.00564 & $\mathbf{0}$ & 0.00245 & 0.0099 & 0 & 0.0024 & 0.745 \\
\hline 8 & 0.00084 & 0.00446 & 0.00679 & $\mathbf{0}$ & 0.00295 & 0.01193 & 0 & 0.0028 & 0.823 \\
\hline 9 & 0.00305 & 0.00417 & 0.00446 & $\mathbf{0}$ & 0.00388 & 0.01297 & 0 & 0 & 0.771 \\
\hline 10 & 0.00322 & 0.00441 & 0.00471 & $\mathbf{0}$ & 0.00409 & 0.0137 & 0 & 0 & 1 \\
\hline
\end{tabular}

\section{The validity of GPDEA when investigating the case of variable returns to scales (VRS)}

In classical VRS model (Banker, Charnes, Cooper 1984), $C_{o}$ is a free variable placed in both the objective function and the inequality constraint. We ran the analysis based on a wrongly formulated VRS model on purpose by considering only $c_{o}$ in the constraint $\sum_{r} u_{r} y_{r j}-\sum_{i} v_{i} x_{i j}+d_{j}=0$ but not in the objective function of MCDEA Model 1 for the Minsum objective function of $\sum_{j} d_{j}$ (see Appendix 3). With the exception of DMU5, we achieved the same efficiency results as Bal et al. (Bal, et al., 2010) with this purposefully intended incorrect formulation! This can be observed by comparing the true values in Table 3 against the efficiency values in Table 5. It can therefore be concluded that GPDEA model under VRS proposed by Bal et al.(Bal, et al., 2010), as seen in Appendix 3, is not an acceptable model as an extension of VRS model (Banker, Charnes, \& Cooper, 1984) for MCDEA. 
Table 5

Minsum DEA-BCC results based on example 1 dataset

\begin{tabular}{|c|c|c|c|c|c|c|c|c|c|}
\hline \multirow[t]{2}{*}{ DMU } & \multicolumn{4}{|c|}{ Output weights } & \multicolumn{4}{|c|}{ Input weights } & \multirow[t]{2}{*}{ Efficiency } \\
\hline & $\mathrm{u}_{1}$ & $\mathrm{u}_{2}$ & $\mathrm{u}_{3}$ & $\mathrm{u}_{4}$ & $\mathrm{v}_{1}$ & $\mathrm{v}_{2}$ & $\mathrm{v}_{3}$ & $\mathrm{~V}_{4}$ & \\
\hline 1 & 0.00762 & 0 & 0.00172 & $\mathbf{0}$ & 0.00155 & 0.01901 & 0 & 0 & 0.765 \\
\hline 2 & 0.0034 & 0.00328 & 0.00307 & $\mathbf{0}$ & 0.00368 & 0.01385 & 0 & 0 & 0.945 \\
\hline 3 & 0.00355 & 0.00343 & 0.00321 & 0 & 0.00385 & 0.01446 & 0 & 0 & 1 \\
\hline 4 & 0 & 0.005 & 0.00821 & $\mathbf{0}$ & 0.00314 & 0.0119 & 0.0003 & 0.0034 & 1 \\
\hline 5 & 0.00491 & 0.00475 & 0.00444 & $\mathbf{0}$ & 0.00532 & 0.02001 & 0 & 0 & 1 \\
\hline 6 & 0.00289 & 0.00279 & 0.00261 & $\mathbf{0}$ & 0.00313 & 0.01178 & 0 & 0 & 0.788 \\
\hline 7 & 0.0052 & 0 & 0.00118 & $\mathbf{0}$ & 0.00106 & 0.01297 & 0 & 0 & 0.718 \\
\hline 8 & 0.00349 & 0.00338 & 0.00316 & $\mathbf{0}$ & 0.00379 & 0.01424 & 0 & 0 & 0.89 \\
\hline 9 & 0.0033 & 0.00319 & 0.00298 & 0 & 0.00358 & 0.01345 & 0 & 0 & 0.824 \\
\hline 10 & 0.0035 & 0.00338 & 0.00316 & $\mathbf{0}$ & 0.00379 & 0.01426 & 0 & 0 & 1 \\
\hline
\end{tabular}

\section{The validity of GPDEA and the issue of zero weights on specific variable for all DMUs}

Table 6 is the same data as used in Bal et al. (Bal, et al., 2010), which is reproduced here for ease of reference. The data consists of 7 departments (DMUs) in a university with the following input and output variables: number of academic staff $\left(x_{1}\right)$, academic staff salaries in thousands of pounds $\left(x_{2}\right)$, support staff salaries in thousands of pounds $\left(x_{3}\right)$, number of undergraduate students $\left(y_{1}\right)$, number of postgraduate students $\left(y_{2}\right)$, number of research papers $\left(y_{3}\right)$.

Table 6

\begin{tabular}{|c|c|c|c|c|c|c|}
\hline \multirow[t]{2}{*}{ DMU } & \multicolumn{3}{|c|}{ Outputs } & \multicolumn{3}{|c|}{ Inputs } \\
\hline & $\mathrm{y}_{1}$ & $\mathrm{y}_{2}$ & $\mathrm{y}_{3}$ & $\mathrm{x}_{1}$ & $\mathrm{x}_{2}$ & $\mathrm{x}_{3}$ \\
\hline 1 & 60 & 35 & 17 & 12 & 400 & 20 \\
\hline 2 & 139 & 41 & 40 & 19 & 750 & 70 \\
\hline 3 & 225 & 68 & 75 & 42 & 1500 & 70 \\
\hline 4 & 90 & 12 & 17 & 15 & 600 & 100 \\
\hline 5 & 253 & 145 & 130 & 45 & 2000 & 250 \\
\hline 6 & 132 & 45 & 45 & 19 & 730 & 50 \\
\hline 7 & 305 & 159 & 97 & 41 & 2350 & 600 \\
\hline
\end{tabular}

When applying the GPDEA model, we first noticed the results reported in Bal et al (Bal, et al., 2010) were incorrect. We therefore reported the correct results in Table 7 to 10. It is easy to observe that the input-output weights do not discriminate well and the GPDEA model cannot be representative of the 
MCDEA model. Based on the correct weights reported in Tables 7 to 10 derived from the analysis, it can be noted that the third input is ignored by almost all DMUs in Tables 7 and 9. Also, the first and third outputs are ignored by all DMUs in Tables 8 and 10 (as it be seen all weights are set to zero). That suggests that these variables have no effect in the efficiency of values of the evaluation!. We will see that in the proposed model of Section 4; we would impose some restrictions on the weights to avoid this issue.

Table 7

GPDEA-CCR results of the university dataset

\begin{tabular}{|c|c|c|c|c|c|c|c|c|}
\hline \multirow[t]{2}{*}{$\mathrm{DMU}$} & \multicolumn{3}{|c|}{ Output weights } & \multicolumn{3}{|c|}{ Input weights } & \multirow{2}{*}{$\begin{array}{l}\text { Efficiency } \\
\text { true values }\end{array}$} & \multirow{2}{*}{$\begin{array}{l}\text { Efficiency } \\
\text { Provided by Bal }\end{array}$} \\
\hline & $\mathrm{u}_{1}$ & $\mathrm{u}_{2}$ & $\mathrm{u}_{3}$ & $\mathrm{v}_{1}$ & $\mathrm{v}_{2}$ & $\mathrm{v}_{3}$ & & \\
\hline 1 & $\mathbf{0}$ & $\mathbf{0}$ & $\mathbf{0}$ & $\mathbf{0}$ & $\mathbf{0}$ & $\mathbf{0}$ & $\mathbf{0}$ & 1 \\
\hline 2 & 0.00333 & 0.00921 & 0.0029 & 0.02019 & 0.00082 & $\mathbf{0}$ & 0.9556 & 0.955 \\
\hline 3 & 0.0016 & 0.00442 & 0.0014 & 0.0097 & 0.00039 & $\mathbf{0}$ & 0.7648 & 0.764 \\
\hline 4 & $\mathbf{0}$ & $\mathbf{0}$ & $\mathbf{0}$ & $\mathbf{0}$ & $\mathbf{0}$ & $\mathbf{0}$ & $\mathbf{0}$ & 0.576 \\
\hline 5 & 0.0013 & 0.00361 & 0.0011 & 0.00791 & 0.00032 & $\mathbf{0}$ & 1 & 1 \\
\hline 6 & 0.00339 & 0.00936 & 0.0029 & 0.02053 & 0.00084 & $\mathbf{0}$ & 1 & 1 \\
\hline 7 & 0.0026 & 0.00218 & 0 & 0 & 0.00041 & $6.4 \mathrm{E}-05$ & 1 & 1 \\
\hline
\end{tabular}

Table 8

GPDEA-BCC results of the university dataset

\begin{tabular}{|c|c|c|c|c|c|c|c|c|}
\hline \multirow[t]{2}{*}{ DMU } & \multicolumn{3}{|c|}{ Output weights } & \multicolumn{3}{|c|}{ Input weights } & \multirow{2}{*}{$\begin{array}{l}\text { Efficiency } \\
\text { true values }\end{array}$} & \multirow{2}{*}{$\begin{array}{l}\text { Efficiency } \\
\text { Provided by Bal }\end{array}$} \\
\hline & $\mathrm{u}_{1}$ & $\mathrm{u}_{2}$ & $\mathrm{u}_{3}$ & $\mathrm{v}_{1}$ & $\mathrm{v}_{2}$ & $\mathrm{v}_{3}$ & & \\
\hline 1 & 0 & 0 & $\mathbf{0}$ & $\mathbf{0}$ & 0 & $\mathbf{0}$ & $\mathbf{0}$ & 1 \\
\hline 2 & 0.00834 & 0.007 & $\mathbf{0}$ & $\mathbf{0}$ & 0.00131 & 0.00021 & 1 & 0.963 \\
\hline 3 & 0.0042 & 0.00353 & $\mathbf{0}$ & $\mathbf{0}$ & 0.00066 & 0.0001 & 0.9603 & 0.813 \\
\hline 4 & 0.01031 & 0.00866 & $\mathbf{0}$ & $\mathbf{0}$ & 0.00162 & 0.00025 & 0.4796 & 0.576 \\
\hline 5 & 0.00311 & 0.00261 & $\mathbf{0}$ & $\mathbf{0}$ & 0.00049 & 7.7E-05 & 1 & 1 \\
\hline 6 & 0.00861 & 0.00722 & $\mathbf{0}$ & $\mathbf{0}$ & 0.00136 & 0.00021 & 1 & 1 \\
\hline 7 & 0.0026 & 0.00218 & $\mathbf{0}$ & $\mathbf{0}$ & 0.00041 & $6.4 \mathrm{E}-05$ & 1 & 1 \\
\hline
\end{tabular}

Table 9

Minsum DEA-CCR results of the university dataset

\begin{tabular}{|c|c|c|c|c|c|c|c|}
\hline \multirow[t]{2}{*}{ DMU } & \multicolumn{3}{|c|}{ Output weights } & \multicolumn{3}{|c|}{ Input weights } & \multirow[t]{2}{*}{ Efficiency } \\
\hline & $\mathrm{u}_{1}$ & $\mathrm{u}_{2}$ & $\mathrm{u}_{3}$ & $\mathrm{v}_{1}$ & $\mathrm{v}_{2}$ & $\mathrm{v}_{3}$ & \\
\hline 1 & 0.00583 & 0.01612 & 0.0051 & 0.03536 & 0.00144 & $\mathbf{0}$ & 1 \\
\hline 2 & 0.00333 & 0.00921 & 0.0029 & 0.02019 & 0.00082 & $\mathbf{0}$ & 0.9556 \\
\hline 3 & 0.0016 & 0.00442 & 0.0014 & 0.0097 & 0.00039 & $\mathbf{0}$ & 0.7648 \\
\hline 4 & 0.00418 & 0.01157 & 0.0036 & 0.02537 & 0.00103 & $\mathbf{0}$ & 0.5769 \\
\hline 5 & 0.0013 & 0.00361 & 0.0011 & 0.00791 & 0.00032 & $\mathbf{0}$ & 1 \\
\hline 6 & 0.00339 & 0.00936 & 0.0029 & 0.02053 & 0.00084 & $\mathbf{0}$ & 1 \\
\hline 7 & 0.00121 & 0.00334 & 0.001 & 0.00732 & 0.0003 & $\mathbf{0}$ & 1 \\
\hline
\end{tabular}


Table 10

Minsum DEA-BCC results of the university dataset

\begin{tabular}{|c|c|c|c|c|c|c|c|}
\hline \multirow[t]{2}{*}{ DMU } & \multicolumn{3}{|c|}{ Output weights } & \multicolumn{3}{|c|}{ Input weights } & \multirow[t]{2}{*}{ Efficiency } \\
\hline & $\mathrm{u}_{1}$ & $\mathrm{u}_{2}$ & $\mathrm{u}_{3}$ & $\mathrm{v}_{1}$ & $\mathrm{v}_{2}$ & $\mathrm{v}_{3}$ & \\
\hline 1 & 0.01575 & 0.01322 & 0 & 0 & 0.00248 & 0.00039 & 0.5639 \\
\hline 2 & 0.00834 & 0.007 & $\mathbf{0}$ & 0 & 0.00131 & 0.00021 & 1 \\
\hline 3 & 0.0042 & 0.00353 & $\mathbf{0}$ & $\mathbf{0}$ & 0.00066 & 0.0001 & 0.9603 \\
\hline 4 & 0.01031 & 0.00866 & $\mathbf{0}$ & 0 & 0.00162 & 0.00025 & 0.4796 \\
\hline 5 & 0.00311 & 0.00261 & $\mathbf{0}$ & 0 & 0.00049 & $7.7 \mathrm{E}-05$ & 1 \\
\hline 6 & 0.00861 & 0.00722 & $\mathbf{0}$ & 0 & 0.00136 & 0.00021 & 1 \\
\hline 7 & 0.0026 & 0.00218 & 0 & 0 & 0.00041 & $6.4 \mathrm{E}-05$ & 1 \\
\hline
\end{tabular}

\section{A new bi-objective multiple criteria (BiO-MCDEA) model}

The aim of this section is to introduce an alternative MCDEA model which is able to provide better weight dispersion and discrimination while allowing multiple criteria to be optimised simultaneously. In our attempt, we seek to avoid the earlier issues raised in the GPDEA models.

Although there are a variety of solution procedures for multi-objective or multi-criteria linear programming (MOLP or MCLP), only goal programming had been suggested for optimizing all objectives simultaneously. The difficulty of a multi-objective problem is not just in finding an optimal solution for each objective function but to find an optimal solution that simultaneously optimizes all objectives. In most cases, no single optimal solution would satisfy all the conditions simultaneously, thus requiring a set of efficient or non-dominated solutions. Further details on MOLP problem can be found in (Cohon, 1987; Dimitris P, 2003).

In Li and Reeves (Li\&Reeves, 1999) proposed MCDEA model, they used the "non-dominated" solution approach. Bal et al. (Bal, et al., 2010) proposed goal programming as an alternative for achieving all objectives simultaneously in the MCDEA model. It has been pointed out in the previous section that the proposed GPDEA models suffer from serious drawbacks. We are compelled therefore to consider an alternative approach to optimise all objectives simultaneously in a MCDEA model, i.e. a bi-objective weighted formulation.

Recalling Li and Reeves (Li \& Reeves, 1999) approach, the MCDEA model's objective functions consistof three parts: $\min \mathrm{d}_{o}, \min M$, and $\min \sum_{j} d_{j}$ as defined in model 1. In a weighted method, the MCDEA's tri-objective function can be restated as follows, $w_{1} d_{o}+w_{2} M+w_{3} \sum_{j} d_{j}$ for the single 
weighted objective equivalent. The weights $w_{i}(i=1,2,3)$ can be varied to obtain different efficient solutions.

However, given that the first objective $w_{1}$ is in fact the equivalent to a conventional CCR model, it can be eliminated from the MCDEA in the weighted objective sense. Besides, Li and Reeves had demonstrated that the first objective yields lower discrimination power as compared to the other two objectives. Hence, for our proposed model, we solved the bi-objective weighted problem using both the second and third objectives. The value of $w_{1}$ is set equal to zero because whenever $\sum_{j} d_{j}$ is minimized, $d_{o}$ will be minimized as well. Thus, we proposed the following model:

Model 3: A new bi-objective MCDEA (Bio-MCDM) model under CRS

$$
\begin{aligned}
& \operatorname{Min} h=\left(w_{2} M+w_{3} \sum_{j} d_{j}\right) \\
& \sum_{i=1}^{m} v_{i} x_{i o}=1, \\
& \sum_{r=1}^{s} u_{r} y_{r j}-\sum_{i=1}^{m} v_{i} x_{i j}+d_{j}=0, \quad j=1, \ldots, n, \\
& M-d_{j} \geq 0, \quad j=1, \ldots, n, \\
& u_{r} \geq \varepsilon, \quad r=1, \ldots, s, \\
& v_{i} \geq \varepsilon, \quad i=1, \ldots, m, \\
& d_{j} \geq 0, \quad j=1, \ldots, n,
\end{aligned}
$$

where $d_{o}$ and $d_{j}(j=1, \ldots, \mathrm{n})$ are the deviation variables for $D M U_{o}$ and the $j_{\text {th }} D M U$ respectively. $D M U_{o}$ is efficient if and only if $d_{o}=0$, otherwise the efficiency value of $D M U_{o}$ is $h_{o}=1-d_{o}$. The effect of constraints $M-d_{j},(j=1, \ldots, n)$ which do not change the feasible region of the solution is merely to make $M$ the maximum deviation. The values of $u_{r}$ and $v_{r}$ are set to be greater than or equal to $\varepsilon$, thus ensuring that this lower bound specification will avoid inputs or the outputs from being ignored by the DMUs. 
We analyzed the dataset of 'Example 1' and the 'university dataset' with the proposed approach. The efficiency values in Table 11 and Table 12 perform better when compared against the actual efficiency values of the GPDEA-CCR models (Table 2 and Table 7, respectively).

Table 11

Model (4) results based on example 1 dataset $(\varepsilon=0.0001)$

\begin{tabular}{|c|c|c|c|c|c|c|c|c|c|c|c|}
\hline \multirow[t]{2}{*}{$\overline{\mathrm{DMU}}$} & \multicolumn{4}{|c|}{ Output weights } & \multicolumn{4}{|c|}{ Input weights } & \multirow[t]{2}{*}{ Efficiency } & \multirow{2}{*}{$\begin{array}{l}\text { Super } \\
\text { Efficiency }\end{array}$} & \multirow[t]{2}{*}{ Rank } \\
\hline & $\mathrm{u}_{1}$ & $\mathrm{u}_{2}$ & $\mathrm{u}_{3}$ & $\mathrm{u}_{4}$ & $\mathrm{v}_{1}$ & $\mathrm{v}_{2}$ & $\mathrm{v}_{3}$ & $\mathrm{v}_{4}$ & & & \\
\hline 1 & 0.0042 & 0.00481 & 0.00573 & 0.0001 & 0.00453 & 0.01678 & 0.0001 & 0.0002 & 0.961 & 0.961 & 4 \\
\hline 2 & 0.0029 & 0.00435 & 0.0048 & 0.0001 & 0.00404 & 0.01324 & 0.0001 & 0.0001 & 0.948 & 0.948 & 5 \\
\hline 3 & 0.00358 & 0.00408 & 0.00488 & 0.0001 & 0.00386 & 0.01429 & 0.0001 & 0.0001 & 1 & 1.21 & 2 \\
\hline 4 & 0.0001 & 0.00486 & 0.00782 & 0.0001 & 0.00344 & 0.01191 & 0.0006 & 0.0029 & 1 & 1.079 & 3 \\
\hline 5 & 0.0042 & 0.00624 & 0.0069 & 0.0001 & 0.00576 & 0.01906 & 0.0001 & 0.0002 & 0.947 & 0.947 & 6 \\
\hline 6 & 0.00245 & 0.00369 & 0.00408 & 0.0001 & 0.00344 & 0.01123 & 0.0001 & 0.0001 & 0.789 & 0.789 & 8 \\
\hline 7 & 0.00116 & 0.00373 & 0.00522 & 0.0001 & 0.00283 & 0.01031 & 0.0001 & 0.0016 & 0.767 & 0.767 & 9 \\
\hline 8 & 0.00147 & 0.00445 & 0.00617 & 0.0001 & 0.00339 & 0.01237 & 0.0001 & 0.0019 & 0.837 & 0.837 & 7 \\
\hline 9 & 0.00279 & 0.00418 & 0.00463 & 0.0001 & 0.00389 & 0.01275 & 0.0001 & 0.0001 & 0.761 & 0.761 & 10 \\
\hline 10 & 0.00294 & 0.00441 & 0.00488 & 0.0001 & 0.0041 & 0.01346 & 0.0001 & 0.0001 & 1 & 1.419 & 1 \\
\hline
\end{tabular}

Table 12

Model (4) results of the university dataset $(\varepsilon=0.0001)$

\begin{tabular}{|c|c|c|c|c|c|c|c|c|c|}
\hline \multirow[t]{2}{*}{ DMU } & \multicolumn{3}{|c|}{ Output weights } & \multicolumn{3}{|c|}{ Input weights } & \multirow[t]{2}{*}{ Efficiency } & \multirow{2}{*}{$\begin{array}{l}\text { Super } \\
\text { Efficiency }\end{array}$} & \multirow[t]{2}{*}{ Rank } \\
\hline & $\mathrm{u}_{1}$ & $\mathrm{u}_{2}$ & $\mathrm{u}_{3}$ & $\mathrm{v}_{1}$ & $\mathrm{v}_{2}$ & $\mathrm{v}_{3}$ & & & \\
\hline 1 & 0.00584 & 0.01619 & 0.00486 & 0.0371 & 0.00138 & 0.0001 & 1 & 1.136 & 3 \\
\hline 2 & 0.00335 & 0.0093 & 0.0027 & 0.022 & 0.00077 & 0.0001 & 0.955 & 0.955 & 5 \\
\hline 3 & 0.00162 & 0.00452 & 0.0012 & 0.0115 & 0.00034 & 0.0001 & 0.763 & 0.763 & 6 \\
\hline 4 & 0.00419 & 0.01162 & 0.00343 & 0.0271 & 0.00097 & 0.0001 & 0.575 & 0.575 & 7 \\
\hline 5 & 0.00133 & 0.00372 & 0.00095 & 0.0098 & 0.00027 & 0.0001 & 1 & 1.171 & 2 \\
\hline 6 & 0.00341 & 0.00947 & 0.00275 & 0.0224 & 0.00078 & 0.0001 & 1 & 1.037 & 4 \\
\hline 7 & 0.00122 & 0.00342 & 0.00086 & 0.0091 & 0.00024 & 0.0001 & 1 & 1.241 & 1 \\
\hline
\end{tabular}

\section{An Application of Energy Dependency among EU member countries}

We further illustrate our proposed model with a 3-inputs and 2-outputs data of 26 European Union (EU) member countries (except Malta) as presented in Appendix 4. Data were based on the EU Emissions Trading Scheme of more than 10,000 installations that generate an excess of $20^{\mathrm{MW}}$ each within the country. This is believed to capture about half of the $\mathrm{CO}_{2}$ emissions within EU. We termed the model as energy dependency as the choice of inputs are based on a set of resources that generate carbon emissions and the output will be the extent of those resources in limiting the carbon effects. The operational definition of the 3 inputs and 2 outputs are as follows: 
Table 13

Model Variables and Operational Definition

\begin{tabular}{ll}
\hline Input Variables & Definition \\
Installation Count $\left(\mathrm{x}_{1}\right)$ & $\begin{array}{l}\text { An installation is a stationary technical unit where one or more } \\
\text { activities are carried out, which could have an effect on } \\
\text { emissions and pollution. }\end{array}$ \\
$\begin{array}{l}\text { Allocated Carbon } \\
\text { Allowances }\left(\mathrm{x}_{2}\right)\end{array}$ & $\begin{array}{l}\text { It is an allowance distributed each year for free to installation } \\
\text { according to the national allocation plan, measured in tonnes } \\
\text { carbon dioxide equivalent. }\end{array}$ \\
$\begin{array}{l}\text { Gross Inland energy } \\
\text { consumption }(\mathrm{GIC}), \text { by } \\
\text { fuel }\left(\mathrm{x}_{3}\right)\end{array}$ & $\begin{array}{l}\text { GIC is the quantity of energy, expressed in oil equivalents, } \\
\text { consumed within the borders of a country. It is calculated as } \\
\text { total domestic energy production plus energy imports and } \\
\text { changes in stocks minus energy exports. }\end{array}$
\end{tabular}

\section{Output Variables}

Electricity Generated From Percentage of gross electricity consumed.

Renewable Sources $\left(\mathrm{y}_{1}\right)$

Share of renewable energy in fuel consumption of transport $\left(\mathrm{y}_{2}\right)$
The degree to which conventional fuels have been substituted by biofuels in transportation.

Although the weights of our proposed Model 4 can be varied to obtain a set of efficiency scores according to the decision analyst's preference, we have set equal objectives such that $w_{2}=\mathrm{w}_{3}=0.5$. The results are presented in Table 14 and compared against Bal et al.'s GPDEA CCR solution in Table 15. The results show that the proposed Model outperforms the GPDEA model; both, in terms of discrimination power and weight dispersion. 
Table 14

Model (4) results of the 26-country dataset $(\varepsilon=0.0001)$

\begin{tabular}{|c|c|c|c|c|c|c|c|}
\hline \multirow[t]{2}{*}{$\mathrm{DMU}$} & \multicolumn{2}{|c|}{ Output Weights } & \multicolumn{3}{|c|}{ Inputs Weight } & \multirow[t]{2}{*}{ Efficiency } & \multirow[t]{2}{*}{ Rank } \\
\hline & $\mathrm{u}_{1}$ & $\mathrm{u}_{2}$ & $\mathrm{v}_{1}$ & $\mathrm{v}_{2}$ & $\mathrm{v}_{3}$ & & \\
\hline Austria & 0.1762 & 0.0165 & 0.0001 & 3.1433 & 0.0001 & 0.1887 & 8 \\
\hline Belgium & 0.4010 & 0.0793 & 5.5165 & 0.0001 & 0.0001 & 0.0669 & 14 \\
\hline Bulgaria & 0.0737 & 0.2344 & 0.0001 & 0.0001 & 9.6501 & 0.0272 & 23 \\
\hline Cyprus & 0.5878 & 1.8698 & 0.0001 & 0.0001 & 76.9715 & 0.4355 & 4 \\
\hline Czech Republic & 0.0348 & 0.1107 & 0.0001 & 0.0001 & 4.5564 & 0.0473 & 17 \\
\hline Denmark & 0.3558 & 0.0703 & 4.8945 & 0.0001 & 0.0001 & 0.1492 & 10 \\
\hline Estonia & 0.2523 & 0.8026 & 0.0001 & 0.0001 & 33.0405 & 0.0417 & 18 \\
\hline Finland & 0.2196 & 0.0434 & 3.0211 & 0.0001 & 0.0001 & 0.0964 & 11 \\
\hline France & 0.0784 & 0.0074 & 0.0001 & 1.3977 & 0.0001 & 0.0210 & 24 \\
\hline Germany & 0.0077 & 0.0243 & 0.0001 & 0.0001 & 0.9998 & 0.0180 & 25 \\
\hline Greece & 0.0473 & 0.1505 & 0.0001 & 0.0001 & 6.1934 & 0.0279 & 21 \\
\hline Hungary & 0.5376 & 0.1063 & 7.3962 & 0.0001 & 0.0001 & 0.0946 & 12 \\
\hline Ireland & 1.1707 & 0.2314 & 16.1047 & 0.0001 & 0.0001 & 0.2952 & 6 \\
\hline Italy & 0.0969 & 0.0091 & 0.0001 & 1.7278 & 0.0001 & 0.0338 & 20 \\
\hline Latvia & 0.9906 & 0.0929 & 0.0001 & 17.6725 & 0.0001 & 0.7431 & 3 \\
\hline Lithuania & 1.2734 & 0.2517 & 17.5175 & 0.0001 & 0.0001 & 0.2279 & 7 \\
\hline Luxembourg & 9.6775 & 1.9132 & 133.1332 & 0.0001 & 0.0001 & 1.0000 & 1 \\
\hline Netherlands & 0.0357 & 0.1135 & 0.0001 & 0.0001 & 4.6723 & 0.0603 & 15 \\
\hline Poland & 0.0148 & 0.0471 & 0.0001 & 0.0001 & 1.9389 & 0.0276 & 22 \\
\hline Portugal & 0.3279 & 0.0307 & 0.0001 & 5.8497 & 0.0001 & 0.1762 & 9 \\
\hline Romania & 0.0405 & 0.1287 & 0.0001 & 0.0001 & 5.2964 & 0.0409 & 19 \\
\hline Slovakia & 0.7222 & 0.1428 & 9.9352 & 0.0001 & 0.0001 & 0.3361 & 5 \\
\hline Slovenia & 1.4516 & 0.2870 & 19.9699 & 0.0001 & 0.0001 & 0.8628 & 2 \\
\hline Spain & 0.1270 & 0.0251 & 1.7470 & 0.0001 & 0.0001 & 0.0592 & 16 \\
\hline Sweden & 0.0981 & 0.0092 & 0.0001 & 1.7505 & 0.0001 & 0.0906 & 13 \\
\hline United Kingdom & 0.0138 & 0.0438 & 0.0001 & 0.0001 & 1.8016 & 0.0151 & 26 \\
\hline
\end{tabular}

Note: The results are based on the normalized version of the raw data provided in Appendix 4 
Table 15

Bal et al.'s GPDEA-CCR results of the 26-country dataset $(\varepsilon=0.0001)$

\begin{tabular}{|c|c|c|c|c|c|c|}
\hline \multirow[t]{2}{*}{$\mathrm{DMU}$} & \multicolumn{2}{|c|}{ Output Weights } & \multicolumn{3}{|c|}{ Inputs Weight } & \multirow[t]{2}{*}{ Efficiency } \\
\hline & $\mathrm{u}_{1}$ & $\mathrm{u}_{2}$ & $\mathrm{v}_{1}$ & $\mathrm{v}_{2}$ & $\mathrm{v}_{3}$ & \\
\hline Austria & 0.0001 & 0.0001 & 0.00089 & 0.0001 & 0.00359 & 0.00018 \\
\hline Belgium & 0.0001 & 0.0001 & 0.00089 & 0.0001 & 0.00359 & 0.00005 \\
\hline Bulgaria & 0.0001 & 0.0001 & 0.00089 & 0.0001 & 0.00359 & 0.00002 \\
\hline Cyprus & 0.0001 & 0.0001 & 0.00089 & 0.0001 & 0.00359 & 0.00002 \\
\hline Czech Republic & 0.0001 & 0.0001 & 0.00089 & 0.0001 & 0.00359 & 0.00005 \\
\hline Denmark & 0.0001 & 0.0001 & 0.00089 & 0.0001 & 0.00359 & 0.00005 \\
\hline Estonia & 0.0001 & 0.0001 & 0.00089 & 0.0001 & 0.00359 & 0.00001 \\
\hline Finland & 0.0001 & 0.0001 & 0.00089 & 0.0001 & 0.00359 & 0.00007 \\
\hline France & 0.0001 & 0.0001 & 0.00089 & 0.0001 & 0.00359 & 0.00009 \\
\hline Germany & 0.0001 & 0.0001 & 0.00089 & 0.0001 & 0.00359 & $0.0000 S$ \\
\hline Greece & 0.0001 & 0.0001 & 0.00089 & 0.0001 & 0.00359 & 0.00003 \\
\hline Hungary & 0.0001 & 0.0001 & 0.00089 & 0.0001 & 0.00359 & 0.00005 \\
\hline Ireland & 0.0001 & 0.0001 & 0.00089 & 0.0001 & 0.00359 & 0.00004 \\
\hline Italy & 0.0001 & 0.0001 & 0.00089 & 0.0001 & 0.00359 & 0.00007 \\
\hline Latvia & 0.0001 & 0.0001 & 0.00089 & 0.0001 & 0.00359 & 0.00009 \\
\hline Lithuania & 0.0001 & 0.0001 & 0.00089 & 0.0001 & 0.00359 & 0.00006 \\
\hline Luxembourg & 0.0001 & 0.0001 & 0.00089 & 0.0001 & 0.00359 & 0.00003 \\
\hline Netherlands & 0.0001 & 0.0001 & 0.00089 & 0.0001 & 0.00359 & 0.00006 \\
\hline Poland & 0.0001 & 0.0001 & 0.00089 & 0.0001 & 0.00359 & 0.00006 \\
\hline Portugal & 0.0001 & 0.0001 & 0.00089 & 0.0001 & 0.00359 & 0.00009 \\
\hline Romania & 0.0001 & 0.0001 & 0.00089 & 0.0001 & 0.00359 & 0.00006 \\
\hline Slovakia & 0.0001 & 0.0001 & 0.00089 & 0.0001 & 0.00359 & 0.00013 \\
\hline Slovenia & 0.0001 & 0.0001 & 0.00089 & 0.0001 & 0.00359 & 0.00008 \\
\hline Spain & 0.0001 & 0.0001 & 0.00089 & 0.0001 & 0.00359 & 0.00008 \\
\hline Sweden & 0.0001 & 0.0001 & 0.00089 & 0.0001 & 0.00359 & 0.00017 \\
\hline United Kingdom & 0.0001 & 0.0001 & 0.00089 & 0.0001 & 0.00359 & 0.00004 \\
\hline
\end{tabular}

Note: The analysis above is based on Bal et al.'s GPDEA-CCR model. The weights and

efficiency values are close to zero, rendering the model to have poor weight dispersion

and discriminant power. The results are based on the normalized version of the raw data provided in Appendix 4.

Comparing the two, it can be easily observed from Table 13 and Table 14 that the efficiency scores from our proposed model could provide easy ranking without any ties. Such is not the case for the GPDEA efficiency scores in Table 14. All the efficiency scores and weights for GPDEA appear to be approximate to zero.

\section{Concluding remarks}


Since 1999 when $\mathrm{Li}$ and Reeves first proposed the MCDEA, there is only but one other proposed solution approach that was suggested for MCDEA, which is the GPDEA. We have shown that the GPDEA models are not alternatives to the MCDEA model. It has major drawbacks in both discrimination power and weight dispersion, aside from the misreported efficiency values of all the tests. Hence, the fair basis of comparison would be between our proposed model and the GPDEA models, given that the MCDEA model merely provided a mathematical formulation with an interactive solution procedure without any emphasis placed on the issues of discrimination power and weight dispersion.

Hence, we have illustrated that our bi-objective multiple criteria DEA model outperforms the GPDEA model in terms of both weight dispersion and discrimination power.

Although we have proposed a bi-objective weighted method for solving the MCDEA model, we stress that there may be other procedures that can be used to extract solutions under multiobjective LP environment. We merely show a procedure that performs better than the GPDEA in terms of ease of formulation and mathematical programming (i.e. less computational codes). We hope that future researchers in DEA will provide better solution procedures for the MCDEA model.

\section{References}

Andersen, P., \&Petersen, N. C. (1993). A procedure for ranking efficient units in data envelopment analysis. Management Science, 39, 1261-1264.

Anderson, T. R., Hollingsworth, K., \&Inman, L. (2002). The fixed weighting nature of a cross-evaluation model Journal of productivity analysis, 17, 249-255.

Bal, H., Örkcü, H. H., \&Çelebioglu, S. (2010). Improving the discrimination power and weights dispersion in the data envelopment analysis. Computers \& Operations Research, 37, 99-107.

Banker, R. D., Charnes, A., \&Cooper, W. W. (1984). Some models for estimating technical and scale inefficiencies in data envelopment analysis. Management Science, 30, 1078-1092.

Charnes, A., Cooper, W. W., Huang, Z. M., \&Sun, D. B. (1990a). Polyhedral Cone-Ratio DEA Models with an illustrative application to large commercial banks. Journal of Econometrics, 46, 73-91.

Charnes, A., Cooper, W. W., Huang, Z. M., \& Sun, D. B. (1990b). Polyhedral cone-ratio models with an illustrative application to large commercial banks Journal of Econometrics, 46, 73-91.

Charnes, A., Cooper, W. W., \&Rhodes, E. (1978). Measuring the efficiency of decision making units. European Journal of Operational Research, 2, 429-444.

Chen, Y.-W., Larbani, M., \&Chang, Y.-P. (2009). Multiobjective data envelopment analysis. Journal of the Operational Research Society, 60, 1556-1566.

Chen, Y. (2005). Measuring super-efficiency in DEA in the presence of infeasibility. European Journal of Operational Research, 161, 447-468.

Cohon, J. L. (1987). Multiobjective Programming and Planning. New York: Academic Press

Dimitris P, M. (2003). Multiobjective programming methods in the reserve selection problem. European Journal of Operational Research, 150, 640-652. 
Doyle, J. R., \&Green, R. H. (1994). Efficiency an cross-efficiency in DEA: derivation, measuring and uses. Journal of the Operational Research Society, 45, 567-578.

Doyle, J. R., \&Green, R. H. (1995). Cross-evaluation in DEA: Improving discrimination among DMUs. INFOR, 33, 205-222.

Dyson, R. G., \&Thanassoulis, E. (1988). Reducing Weight Flexibility in Data Envelopment Analysis. Journal of the Operational Research Society, 39, 563-576.

Emrouznejad, A., Parker, B. R., \&Tavares, G. (2008). Evaluation of research in efficiency and productivity: A survey and analysis of the first 30 years of scholarly literature in DEA. Socio-Economic Planning Sciences, $42,151-157$.

Green, R. H., Doyle, J. R., \&Cook, W. D. (1996). Preference voting and project ranking using DEA and crossevaluation. European Journal of Operational Research, 90, 461-472.

Ignizio, J. P. (1976). Goal programming and extensions. Lexington: Lexington Books.

lee, S. M. (1972). Goal programming for decision analysis. Philadelphia: Auerback.

Li, X.-B., \&Reeves, G. R. (1999). A multiple criteria approach to data envelopment analysis. European Journal of Operational Research, 115, 507-517.

Sexton, T. R., Silkman, R. H., \&Hogan, A. J. (1986). The methodology of data envelopment analysis In R. H. Silkman (Ed.), Measuring efficiency: An assessment of data envelopment analysis (pp. 7-29). San Fransisco: Jossey-Bass.

Thanassoulis, E., \&Allen, R. (1998). Simulating Weights Restrictions in Data Envelopment Analysis by Means of Unobserved DMUs. Management Science, 44, 586-594.

Thompson, R. G., F. D. Singleton Jr., Thrall, R. M., \&Smith, B. A. (1986). Comparative Site Evaluations for Locating a High-Energy Physics Lab in Texas. INTERFACES, 16, 35-49.

Thompson, R. G., Langemeier, L. N., Lee, C. T., \&Thrall, R. M. (1990). The role of multiplier bounds in efficiency analysis with application to Kansas farming. Journal of Econometrics, 46, 93-108.

Appendix 1:

Goal programming DEA model under variable returns to scale as proposed in $\mathrm{Bal}$ et al's (Bal, et al., 2010) (see also appendix 3)

$$
\begin{aligned}
& \min a=\left\{d_{1}^{-}+d_{1}^{+}+d_{2}^{+}+\sum_{j} d_{3 j}^{-}+\sum_{j} d_{j}\right\} \\
& \sum_{i=1}^{m} v_{i} x_{i o}+d_{1}^{-}-d_{1}^{+}=1, \\
& \sum_{r=1}^{s} u_{r} y_{r o}+c_{o}+d_{2}^{-}-d_{2}^{+}=1, \\
& \sum_{r=1}^{s} u_{r} y_{r j}-\sum_{i=1}^{m} v_{i} x_{i j}+c_{o}+d_{j}=0, \quad j=1, \ldots, n, \\
& M-d_{j}+d_{3 j}^{-}-d_{3 j}^{+}=0, \quad j=1, \ldots, n, \\
& u_{r} \geq 0, \quad r=1, \ldots, s,
\end{aligned}
$$




$$
\begin{aligned}
& v_{i} \geq 0, \quad i=1, \ldots, m, \\
& d_{j} \geq 0, \quad j=1, \ldots, n, \\
& d_{1}^{-}, d_{1}^{+}, d_{2}^{-}, d_{2}^{+} \geq 0, \\
& d_{3 j}^{-}, d_{3 j}^{+} \geq 0, \quad j=1, \ldots, n, \\
& c_{o} \text { free in sign }
\end{aligned}
$$

Appendix 2:

\section{Proof of logical invalidity of GPDEA formulation}

From Bal el al.'s GPDEA-CCR model (2):

$$
\begin{gathered}
\sum_{r=1}^{s} u_{r} y_{r o}+d_{2}^{-}-d_{2}^{+}=1 \\
\sum_{i=1}^{m} v_{i} x_{i o}+d_{1}^{-}-d_{1}^{+}=1 \\
\sum_{r=1}^{s} u_{r} y_{r j}-\sum_{i=1}^{m} v_{i} x_{i j}+d_{j}=0
\end{gathered}
$$

Multiplying equality (II) by -1 :

$$
-\sum_{i=1}^{m} v_{i} x_{i o}-\left(d_{1}^{-}-d_{1}^{+}\right)=-1
$$

adding (I)and (IV)yields:

$$
\sum_{r=1}^{s} u_{r} y_{r o}-\sum_{i=1}^{m} v_{i} x_{i o}+d_{2}^{-}-d_{2}^{+}-\left(d_{1}^{-}-d_{1}^{+}\right)=0
$$

Suppose that $j=o$ in equality $(I I I)$ :

$$
\sum_{r=1}^{s} u_{r} y_{r o}-\sum_{i=1}^{m} v_{i} x_{i o}+d_{o}=0 \quad(V I)
$$

By considering $(V),(V I)$, it can be concluded: $d_{o}=d_{2}^{-}-d_{2}^{+}-\left(d_{1}^{-}-d_{1}^{+}\right)$ 
Since the efficiency value for DMU under evaluation, $h_{o}$, must be equal to $\sum_{r=1}^{s} u_{r} y_{r o},(I)$ can be restated as:

$$
h_{o}=\sum_{r=1}^{s} u_{r} y_{r o}=1-\left(d_{2}^{-}-d_{2}^{+}\right)
$$

Since $h_{o}=1-d_{o}$ in classical DEA, $d_{o}=\left(d_{2}^{-}-d_{2}^{+}\right)$in $(V I I I)$. Therefore, the value of $d_{1}^{-}-d_{1}^{+}$in $(V I I)$ must be equal to zero to render correctness. Nonetheless, in Bal el al.'s GPDEA models, the weighted sum of inputs for DMU under evaluation $\sum_{i=1}^{m} v_{i} x_{i o}$, can be zero or less than unity, which is highly problematic. Without loss of generality, the same problem applies to the GPDEA-BCC model.

Appendix 3:

\section{Minsum BCC-DEA model under variable returns to scale, a wronglv formulated VRS model}

$$
\begin{aligned}
& \min \sum_{j=1}^{n} d_{j} \\
& \sum_{i=1}^{m} v_{i} x_{i o}=1, \\
& \sum_{r=1}^{s} u_{r} y_{r j}-\sum_{i=1}^{m} v_{i} x_{i j}+c_{o}+d_{j}=0, \quad j=1, \ldots, n, \\
& M-d_{j} \geq 0, \quad j=1, \ldots, n, \\
& u_{r} \geq 0, \quad r=1, \ldots, s, \\
& v_{i} \geq 0, \quad i=1, \ldots, m, \\
& d_{j} \geq 0, \quad j=1, \ldots, n, \\
& c_{o} \text { free in sign }
\end{aligned}
$$


Appendix 4:

\section{$\underline{\text { The Energy Dependency Dataset }}$}

Dataset of 26 countries

\begin{tabular}{|c|c|c|c|c|c|}
\hline \multirow[t]{2}{*}{ Countries } & \multicolumn{2}{|l|}{ Outputs } & \multicolumn{3}{|l|}{ Inputs } \\
\hline & $\mathrm{Y}_{1}$ & $Y_{2}$ & $\mathrm{X}_{1}$ & $\mathrm{X}_{2}$ & $\mathrm{X}_{3}$ \\
\hline Austria & 66.793 & 6.5 & 225 & 8810 & 31887710 \\
\hline Belgium & 6.083 & 3.3 & 362 & 2242 & 56797576 \\
\hline Bulgaria & 9.808 & 0.6 & 146 & 1087 & 40591231 \\
\hline Cyprus & 0.073 & 2.0 & 13 & 98 & 5089082 \\
\hline Czech Republic & 6.783 & 3.4 & 425 & 2425 & 85968002 \\
\hline Denmark & 27.390 & 0.4 & 408 & 3242 & 23912314 \\
\hline Estonia & 6.105 & 0.2 & 56 & 717 & 11855527 \\
\hline Finland & 25.777 & 2.3 & 661 & 7887 & 37069940 \\
\hline France & 13.547 & 6.0 & 1125 & 19811 & 128660709 \\
\hline Germany & 16.200 & 5.7 & 1997 & 27693 & 391714624 \\
\hline Greece & 12.276 & 1.1 & 162 & 1861 & 63246705 \\
\hline Hungary & 6.988 & 3.1 & 270 & 1854 & 23844843 \\
\hline Ireland & 13.925 & 1.9 & 124 & 641 & 19951911 \\
\hline Italy & 20.536 & 3.8 & 1201 & 16026 & 208982856 \\
\hline Latvia & 49.232 & 1.2 & 111 & 1567 & 3532491 \\
\hline Lithuania & 5.505 & 4.2 & 114 & 874 & 7573712 \\
\hline Luxembourg & 3.678 & 2.1 & 15 & 121 & 2488229 \\
\hline Netherlands & 9.152 & 4.2 & 443 & 3148 & 83834170 \\
\hline Poland & 5.804 & 4.8 & 943 & 6265 & 202011597 \\
\hline Portugal & 33.267 & 3.6 & 280 & 4734 & 30902050 \\
\hline Romania & 27.916 & 1.6 & 275 & 5270 & 73956515 \\
\hline Slovakia & 17.880 & 8.6 & 201 & 1214 & 32140581 \\
\hline Slovenia & 36.783 & 1.9 & 100 & 887 & 8216051 \\
\hline Spain & 25.747 & 3.5 & 1143 & 12091 & 150707494 \\
\hline Sweden & 56.378 & 7.3 & 821 & 15819 & 21103878 \\
\hline United Kingdom & 6.664 & 2.7 & 1140 & 6214 & 217404830 \\
\hline
\end{tabular}

Note: The data are taken from three databases: European commision's Eurostat, Carbonmarketdata.com and i-insights.com 